Dear Author,

Please, note that changes made to the HTML content will be added to the article before publication, but are not reflected in this PDF.

Note also that this file should not be used for submitting corrections. 


\title{
Seasonal fluctuation of riverine navigation and accessibility in Western Amazonia: An analysis combining a cost-efficient ¿9 GPS-based observation system and interviews
}

\author{
o8 Henrikki Tenkanen ${ }^{\text {a, }}$, Maria Salonen ${ }^{a}$, Matti Lattu ${ }^{\text {b }}$, Tuuli Toivonen ${ }^{\text {a, c }}$ \\ ${ }^{a}$ Department of Geosciences and Geography, University of Helsinki, P.O. Box 64 Gustaf Hällströmin katu 2, 00014, Finland \\ ${ }^{\mathrm{b}}$ Department of Teacher Education, University of Helsinki, P.O. Box 9 Siltavuorenpenger 5, 00014, Finland \\ $01{ }^{\mathrm{c}}$ Department of Biosciences, University of Helsinki, P.O. Box 56 Viikinkaari 9, 00014, Finland
}

\section{A R T I C L E I N F O}

Article history:

Received 7 January 2015

Received in revised form

8 May 2015

Accepted 6 July 2015

Available online $\mathrm{xxx}$

Keywords:

Accessibility

Transportation

Amazonia

GPS-Tracking

GIS

Mobility

Seasonality

Interviews

\begin{abstract}
A B S T R A C T
Accessibility and transportation possibilities are key factors influencing societal conditions and land use patterns in rural areas. Thus, information on the spatial patterns of accessibility and transportation can be of paramount importance in understanding regional differences in development, human livelihood and land use patterns. Analysing spatio-temporal transportation patterns is particularly challenging in areas where everyday transportation is based on unscheduled public transportation and a naturally controlled seasonal transportation network, such as rivers. Here, our aim is to provide information on the seasonal dynamics of riverine transportation and its effects on accessibility patterns in Peruvian Amazonia. We analysed riverine transportation speeds using a low-cost GPS-based riverboat observation system. Spatio-temporal accessibility patterns were generalised from the GPS-observations that were classified according to seasons into the high water season, intermediate season and low water season. We show that navigation along the rivers has a clear seasonal and directional (upstream/downstream) variation, which varies with different types of rivers based on channel morphology. In addition, we conducted interviews with local people to study their perceptions of the seasonal changes in navigation and the accuracy of transportation schedules. As the travel distances in Peruvian Amazonia are generally long, seasonal and directional differences have clear impacts on the overall accessibility patterns in the area and on the livelihoods of riverine inhabitants. Furthermore, the lack of clearly scheduled transportation causes considerable uncertainty about transportation options for local communities. The baseline information of the seasonal and directional variation of riverine transportation and travel speeds provided by our work is usable in further accessibility and livelihood analyses for Peruvian Amazonia, but it may also be useful in other areas relying on riverine transportation.
\end{abstract}

(C) 2015 Published by Elsevier Ltd.

\section{Introduction}

The concept of accessibility, defined as the degree of connectivity between places (Ingram, 1971) or as a measure of potential for interaction (Hansen, 1959), has become an increasingly important and widely used analytical tool as a means of understanding the spatial relationships between societies and the environment. Accessibility is widely recognised as being one of the key factors affecting regional economic development, land-use changes and societal conditions (Agarwal, Rahman, \& Errington, 2009; Kirby et al., 2006; Laurance et al., 2001, 2002, 2012; Verburg \& Ellis, \& Letourneau, 2011). Transport options between rural communities and market centres is also closely related to rural livelihoods, since it influences, for instance, the abilities of rural dwellers to sell their produce in markets (Olsson, 2009; Salonen, Toivonen, Cohalan, \& Coomes, 2012; Takasaki, Barham, \& Coomes, 2001), get services, such as education or healthcare (Siedner et al., 2013; Vasconcellos, 1997), and obtain information and participate in decision-making (Reyes-García, Vadez, Aragón, Huanca, \& Jagger, 2010).

Accessibility patterns are constantly changing, both spatially and temporally. Modifications of transportation networks and service structures cause spatial changes (Abizaid, 2005; Curtis \& Scheurer, 2010; Karou \& Hull, 2014), while yearly/monthly/ diurnal changes in transit schedules and people's locations cause

\footnotetext{
Corresponding author.

E-mail address: henrikki.tenkanen@helsinki.fi (H. Tenkanen).
}

http://dx.doi.org/10.1016/j.apgeog.2015.07.003

0143-6228/@ 2015 Published by Elsevier Ltd. 
continuous temporal dynamism (Farber, Morang, \& Widener, 2014; Järv, Ahas, \& Witlox, 2014). Temporal variation in accessibility (and in spatial mobility) is often discussed in the literature (Andrienko et al., 2010; Kvist, Gram, Cacares, \& Ore, 2001; Kwan, 2013; Salonen et al., 2012); however, until recently, accessibility has mainly been quantified only in static spatial terms. In observed spatial mobility, the temporal dimension comes naturally as part of the concept, since the movement of an object consists of both spatial and temporal components (Andrienko, Andrienko, Pelekis, \& Spaccapietra, 2008). A vast amount of spatio-temporal data has become available with the fast development of Information and Communication Technologies (ICT) and different monitoring systems over the last two decades. Thus, extracting knowledge from GPS-based trajectories has recently gained a lot of attention in the scientific field (Dodge, Weibel, \& Lautenschütz, 2008; Giannotti \& Q4 Pedreschi, 2008; 2012; Willems, Van de Wetering, \& Wijk, 2009). Indeed, mobility-based "observational accessibility" could provide more detailed, yet easily adaptable, concepts for spatio-temporal accessibility measures.

The transportation realities of rural areas in developing regions differ quite significantly from those of modern urban areas with tightly scheduled public transportation systems. Limited transportation options, lacking transportation infrastructures and inaccurate schedules can influence considerably livelihood possibilities and development in rural areas. In Peruvian Amazonia, the transportation realities are particularly challenging, and many of the regional differences in development, human livelihoods and land use seem to be linked to accessibility (Salonen et al., 2012; Salonen, Maeda \& Toivonen, 2014; Shanley, Luz, \& Swingland, 2002). The area lacks comprehensive road infrastructure (Abizaid, 2005; Coomes, Abizaid, \& Lapointe, 2009); the great majority of people and cargo are transported by riverboats and larger vessels (Ministerio de Transportes y Comunicaciones, 2010; Rodriguez Achung, 1994). Travelling in the area is strongly influenced by natural forces: seasonal differences in water levels affect the ability to access different areas during changing seasons (Kvist et al., 2001). The riverine environment in the study area is extremely dynamic by nature, as the water levels may vary more than $10 \mathrm{~m}$ between seasons (SEHINAV, 2014), thus, affecting significantly human activities in the area such as food production, economic use of flood plains and transportation of people and products (Abizaid, 2005; Coomes et al., 2009; Kvist \& Nebel, 2001; Shanley et al., 2002). Therefore, having sufficient understanding of the regional transportation realities and spatiotemporal accessibility patterns is critical in understanding land use patterns, livelihood options and human well-being, as well as their change, in the area.

In this paper, we demonstrate how seasonality and direction of movement affect the navigation of vessels and spatio-temporal accessibility patterns in Western Amazonia. For studying the seasonal variation of accessibility in the area, we developed a low-cost, GPS-based tracking system, which $i$ is used to track the movements of local riverboats and record their speeds along the Amazonian rivers. We used the system to track riverboat movement in 2012 and 2013.

Even though transportation characteristics of professional (mainly maritime) vessels have been studied before (e.g., Demsar \& Virrantaus, 2010; Makkonen, Salonen, \& Kajander, 2013), to our knowledge, this is the first study to include such a temporal analysis of riverine transportation in Western Amazonia. To enrich the quantitative data, we also interviewed riverboat passengers about their experiences on the accuracy of the transportation schedules and about seasonal changes in travel times, thus, making it possible to evaluate perceived accessibility based on people's own thoughts. With these data, we aim to 1) analyse the seasonal transportation characteristics of the main transportation routes in Western
Amazonia and 2) understand the variation of the spatio-temporal accessibility patterns in riverine Amazonia and the factors that affect these patterns. Findings of this study can provide valuable quantitative information for the planners and decision makers of the study area about the realities of travelling in Peruvian Amazonia. Our approach could also provide better service for local riverine passengers in terms of more accurate transportation schedules for the vessels that are currently relatively inaccurate.

\section{Study area}

Our study area comprises the Loreto region and northern parts of the Ucayali region in northeastern Peru, Western Amazonia (Fig. 1). The extensive fluvial system of the area consists of thousands of rivers that have a strong influence over the dynamisms of natural habitats, as well as on human livelihood (Abizaid, 2005; Puhakka, Kalliola, Rajasilta, \& Salo, 1992; Salo et al., 1986). Fig. 1 shows the largest rivers in the study area: the Amazon, Marañon, Ucayali and Huallaga. The channel morphology of the rivers in the study area varies from wide anastomosing rivers with low sinuosity (e.g., the Amazon and Marañón) to narrower meandering rivers with higher sinuosity (e.g., the Ucayali and Huallaga) (Puhakka et al., 1992; Sioli, 1984; Toivonen, Mäki, \& Kalliola, 2007).

Seasonal dynamics in Amazonian rivers are major: the difference in water levels between seasons can be over $10 \mathrm{~m}$ (Fig. 1), and lateral migration rates can reach hundreds of meters per year (Abad et al., 2013; Kalliola et al., 1992). Such seasonal changes and flood cycles of the Amazonian river system are also able to modify extensive land areas in river floodplains (Marengo, 2005; Zeng, 1999).

Iquitos is the capital of the Loreto region with an estimated population of 422,000 in 2012 (the sixth largest city in Peru (INEI, 2012)). It is a commercially important centre, located at the confluence of the Amazon, Nanay and Itaya rivers, approximately $100 \mathrm{~km}$ north of the confluence of the Ucayali and Marañon rivers that originate from the Andes and form the Amazon River (Fig. 1). Connections from Iquitos to coastal Peru, such as the capital of Lima, either go through airways or use a combination of river and road transport. If the latter connection is used, one needs to travel by waterway first to either Yurimaguas (in the south-western Loreto region) or to Pucallpa (the capital of the Ucayali region), as both have road connections to the rest of the country (Fig. 1). Along these main fluvial routes (Iquitos-Yurimaguas; Iquitos-Pucallpa), the frequency of transportation is high and the capacity of the river launches operating along these routes is typically large (Salonen et al., 2012); along smaller tributaries, in areas where smaller boats operate, both boat frequency and boat capacities are typically much lower.

\section{Materials and methods}

\subsection{Mobility data}

Studying the spatio-temporal accessibility of riverine transportation in Amazonia required developing a specific observation system of our own called Amazonian Riverboat Observation System (AROS). AROS resembles the Automatic Identification System that is used in professional maritime vessel tracking, but since such a system is not used in Peruvian Amazonia, AROS was developed. Low cost GPS-based satellite messengers (SPOT, 2014) aboard collaborating river launches were used to track the movements of the vessels and send the data via communication satellites to our database (sample rate $=10 \mathrm{~min}$ ). Five individual vessels tracked their movements continuously during 2012 and 2013, thus, forming the most important data source used in this study (Table 1). Even 


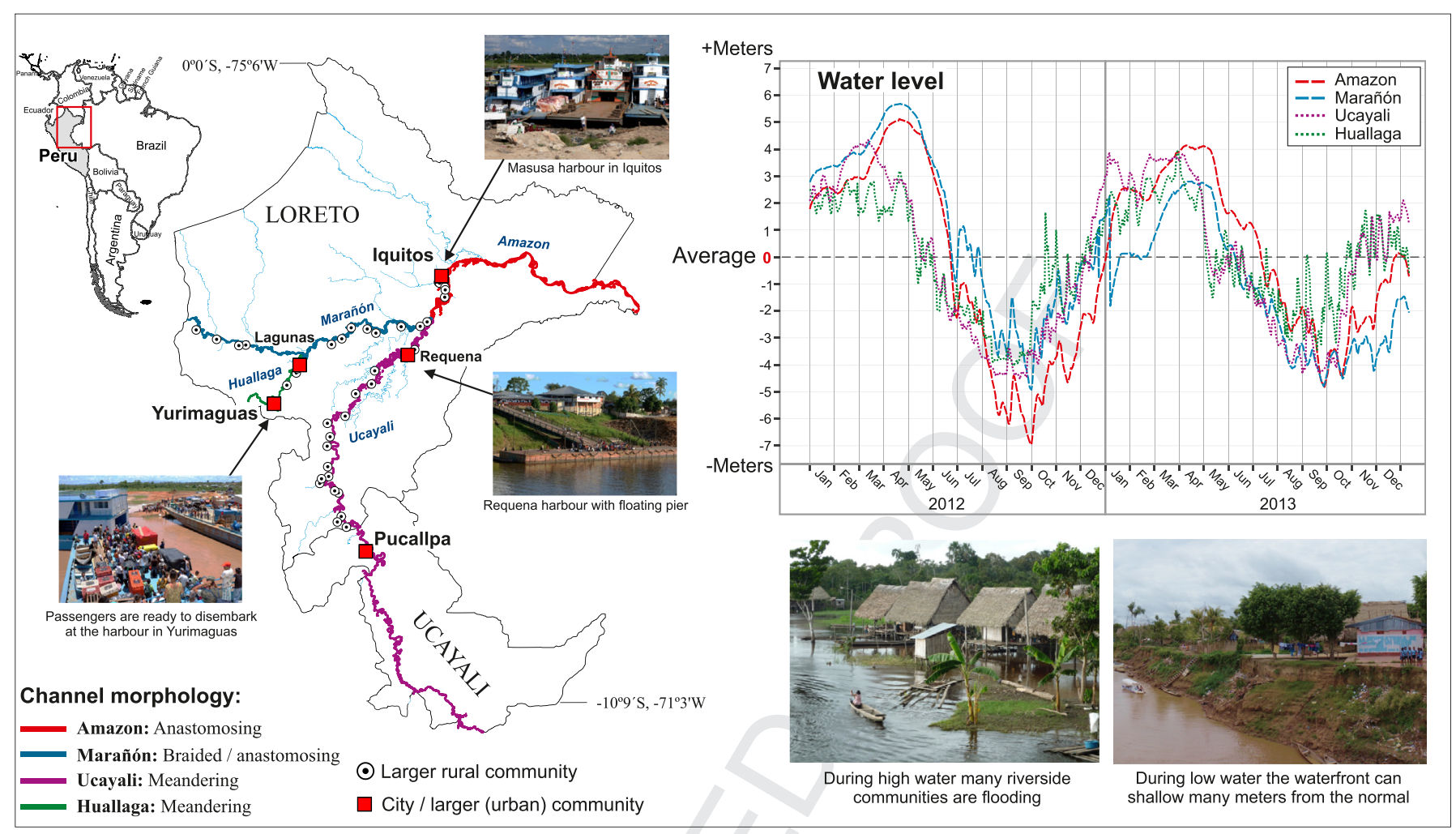

Fig. 1. Map of rivers included in this study and their channel types according to Puhakka et al. (1992) and Toivonen et al. (2007), populated places along the rivers ( $>50$ inhabitants), and daily water levels of individual rivers in 2012 and 2013 represented as a difference from the two-year average river height Source: SEHINAV, 2014.

Table 1

Datasets used in the study.

\begin{tabular}{lll}
\hline Data & Source & Data collection time \\
\hline Mobility data & GPS-data from AROS $(\mathrm{n}=27,634)$ & January 2012-December 2013 \\
River network/geometry & GPS- data from AROS $(\mathrm{n}=46,230)$ & August 2011-February 2014 \\
Travel survey & Semi-structured interviews with passengers on-board collaborating vessels $(\mathrm{n}=76)$ & October 2012 \\
Water level statistics & SEHINAV (2014) & January 2012-December 2013 \\
River classification & GOREL (2006); Puhakka et al. (1992); Toivonen et al. (2007) & \\
Administrative borders & GOREL (2006) & \\
Populated places & GOREL (2006) & \\
\hline
\end{tabular}

though the GPS-data is collected with separate vessels, we mainly use all of the data at the same time when presenting our results, since all of the vessels are rather similar by design and equipment and have fairly equivalent travel speeds. Tracked vessels were large launches (lanchas) that are specifically designed for navigating along rivers. They operate on long distance journeys and can carry 150-300 passengers, and 35-600 tonnes of cargo (Salonen et al., 2012). GPS-data consist of five different attributes: vessel-id, coordinates, timestamp, Unix time, and message type (test/tracking).

\subsection{Water level statistics}

For studying the relation between river dynamics and vessel movement characteristics, we used statistics of daily water levels in the study area that were measured from four different measurement points along the main Amazonian rivers: Río Amazonas in Iquitos, Río Marañon in Nauta, Río Ucayali in Pucallpa and Río Huallaga in Yurimaguas (SEHINAV, 2014). Water levels were classified into three seasonal classes following a classification used by SEHINAV: high water season (01/March-31/May), low water season (01/August-31/October) and an intermediate season (01/ June-31/July and 01/November-28/February).

\subsection{Calculation of movement characteristics}

Analysis of mobility data based on GPS-devices has gained a lot of attention in the scientific literature with different approaches and emphases (e.g., Andrienko et al., 2008, 2010; Downs \& Horner, 2012); thus, various techniques have been developed to analyse movement characteristics of different Moving Point Objects (Dodge et al., 2008). Data from our GPS-devices does not include any traditional details about the movement such as travel speed or direction of movement. Thus, these characteristics were calculated with a specific algorithm ${ }^{1}$ that was developed for statistical programme R. Since the travel speed of the collaborating vessels are fairly constant (max speed $\sim 25 \mathrm{~km} / \mathrm{h}$ ), and the potential navigation paths are highly constrained by the river channels, it was possible

\footnotetext{
1 http://github.com/AccessibilityRG/TRAT.
} 
to use a simple algorithm to extract details about the movement from the GPS points.

Our algorithm calculates measurable movement parameters from the data (including speed and direction of movement) and detects individual journeys. The algorithm uses a linear referencing technique to calculate the correct network distances between consecutive observations by associating each AROS observation with a known point on the river network, which is then used to determine the correct travel speed and direction of movement. Differentiating an individual journey from another is done by filtering the data based on information about direction of movement (upstream vs. downstream) and stationary time (threshold $=36 \mathrm{~h}$ ), which indicates that a vessel is staying at harbour. More details of our algorithm can be found in Tenkanen, Salonen, Lattu, and Toivonen (2014).

\subsection{Predicting the travel speed of the vessels with linear regression models}

For studying how seasonal changes in water levels and direction of movement affect navigation, the following linear regression models were formed and fitted:

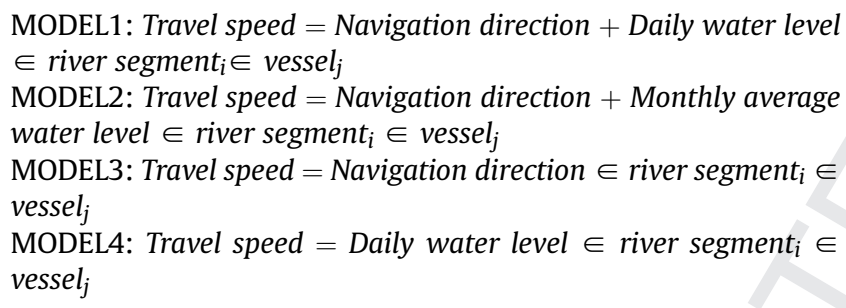

Travel speed indicates the average travel speed that was measured along an individual river stretch, excluding possible stationary time spent at harbours. The daily water level was determined for each river segment separately, which indicates the value from the day when the vessel arrives at the destination or the day when the vessel starts navigating along another river segment. Navigation direction is either upstream or downstream, and the values were dummy-coded into binary form (0/1). When averaging the values from multiple vessels, the $\mathrm{R}^{2}$ values were weighted by the number of observed trajectories of each vessel to make the results more robust. Calculations were done in $\mathrm{R}$.

\subsection{Calculation of accessibility isochrones}

There are various ways to define and measure accessibility; however, in this study, we focus on the transportation and temporal components, as defined by Geurs and van Wee (2004). We define accessibility as the degree to which two places on the same surface are connected (Ingram, 1971), and we measure accessibility as time distance between places. Quantifying accessibility using time as a unit of distance is particularly important in riverine environments, such as in Peruvian Amazonia, where straight-line Euclidian distances differ considerably compared to network distances (Salonen et al., 2012), and the changing water levels of rivers causes continuous variation in travel time distances between seasons.

Generalising the seasonal movement characteristics into a spatio-temporal context was done by calculating accessibility isochrones that show how far it is possible to reach within certain temporal constraints along a specific navigation route from selected cities when travelling upstream or downstream. The chosen time constraints are six and $12 \mathrm{~h}$, and the selected cities are Requena and Lagunas. Results are based on movement characteristics only (i.e., stationary time spent at the harbours is omitted).
Network distance from the selected city was calculated based on seasonal average travel speed information on upstream/downstream within specific time constraints $(6 / 12 \mathrm{~h})$ with the following formula: (Travel speed $\in$ season $\in$ direction)*time. Results are presented as average accessibility, measured as travel time based on AROS observations from 2012 to 2013. Annual variation is presented as bars under the dashed accessibility isochrones.

\subsection{Interviews}

Whereas our previous approaches are focusing on quantifying the movement characteristics based on GPS-measurements, we also wanted to ask people about their own conceptions of the realities of travelling in the study area. After all, they are the ones who are affected the most by the varying transportation schedules. We surveyed passengers $(n=74)$ on-board collaborating vessels during a fieldwork period in October 2012. In the surveys, the interviewees were asked about their travel experiences, focusing especially on their conception about seasonal and directional variation of travel times of the trips that they usually take and the accuracy of schedules of the vessels. They were also asked to estimate the travel times of the trips to/from their home location to specific wellknown locations during high and low water. These estimations were used to calculate seasonal and directional variation in travel times based on passengers' estimates. In addition, we asked foe details about their current trip, including information about the origin and destination harbours, as well as background information about the respondent's age, sex and their place of residence. Fiftyseven per cent of the respondents were male, with an average age of 43 years; forty-three per cent were female, with an average age of 34 years. Thirty-two per cent of the respondents were living in larger cities ( $>50,000$ residents), while $68 \%$ were living in mediumsized or small rural communities.

\section{Results}

\subsection{Measured movement characteristics}

Seasonal movement characteristics of vessels operating along individual rivers are shown in Table 2. Reported travel speeds indicate the average travel speed of upstream or downstream journeys based on $\mathrm{N}$ number of tracked trajectories along an individual river. Travel speeds ranged between 13.4 and $18.0 \mathrm{~km} / \mathrm{h}$ downstream and $10.6-15.2 \mathrm{~km} / \mathrm{h}$ upstream during the entire study period. Highest travel speeds were recorded along the Amazon proper when navigating downstream during high water in 2013. Lowest speeds, in turn, were recorded when traveling upstream on the Marañón River during low water in 2012. The standard deviation of travel speeds demonstrates the stability of navigation along the rivers. Travel speeds were most stable along the Huallaga River with lowest overall variance, and most unstable along the Amazon River with highest variance in travel speeds. Regarding season, the variance of average travel speed was highest during low water and lowest during high water. It was, in total, approximately $8 \%$ faster to navigate along the rivers in 2013 compared to 2012.

Comparing the travel speeds along anastomosing rivers (the Amazon, Marañón) to meandering rivers (the Ucayali, Huallaga) shows that there is some evidence of river morphology affecting navigation; for instance, navigation along the Ucayali was generally slower than along the Amazon River. However, there is no clear trend visible in the data that would indisputably confirm this finding since there is significant seasonal, annual and river-wise variation in the results.

There are clear differences in travel speeds to different navigation directions and between different seasons (Table 3). Results 




show that seasonal differences in travel speeds were highest between high and low water. The highest seasonal difference along an individual river was downstream the Ucayali in 2012 when it was $28 \%$ faster to navigate during high water compared to low water ( $8 \mathrm{~h}$ difference over $500 \mathrm{~km}$ ). Comparing the values of anastomosing rivers (the Amazon, Marañón) to meandering rivers (the Ucayali, Huallaga) shows that the seasonal differences in travel speed are greater along meandering rivers ( $\max =9 \%$ higher).

Directional differences in navigation were highest along the Marañón River (mean $=38 \%$ ) and lowest along the Huallaga River (mean $=18 \%$ ). Overall, it was $26 \%$ faster to navigate downstream than upstream.

\subsection{Measured navigation characteristics}

Fig. 2 shows the average travel speeds and travel times of all individual trips along two different routes and daily water levels of the dominant river along routes in 2012 and 2013. Route 1 (length: $1120 \mathrm{~km}$ ) goes between Iquitos and Pucallpa along the Amazon and Ucayali rivers, and Route 2 (length: $680 \mathrm{~km}$ ) goes between Iquitos and Yurimaguas along the Amazon, Marañón and Huallaga rivers. Route 1 consists of trips travelled by three individual vessels, while, on Route 2 , there were two operating vessels that were tracked. Results show that, on Route 1, travel speeds were generally highest between February and April, and on Route 2, they were highest between March and May when travelling downstream (average velocity $\sim 18 \mathrm{~km} / \mathrm{h}$ ). Thus, a downstream trip on Route 1 (from Pucallpa to Iquitos) would take approximately $62 \mathrm{~h}$ (2.6 days), and a downstream trip on Route 2 (from Yurimaguas to Iquitos) would take $38 \mathrm{~h}$ (1.6 days) during those months. Slowest travel speeds were observed during September on both routes when it would take approximately $100 \mathrm{~h}$ (4.2 days) downstream on Route $1(\sim 11 \mathrm{~km} / \mathrm{h})$, and $60 \mathrm{~h}$ (2.5 days) upstream on Route 2 $(\sim 11 \mathrm{~km} / \mathrm{h})$. The highest seasonal difference for navigating a route in the same direction was approximately $43 \mathrm{~h}$ on Route 1 , and $19 \mathrm{~h}$ on Route 2, which were both observed when travelling downstream in 2013.

\subsection{Explanatory variables of travel speed in the riverine environment}

The comparison between travel speeds and daily water levels reveals that water level affects navigation, especially when travelling downstream, since there are visible changes in travel speeds in a similar manner, as in water levels (Fig. 2). On the contrary, when travelling upstream, the travel speeds are relatively constant throughout the year, indicating that varying water levels have less of an impact on upstream navigation and overall travel times. The connections between downstream travel speeds and water levels are clearly visible, especially along Route 1 in 2012 and along Route 2 in 2013. Calculating correlations (see Fig. 2) between the average travel speed of an individual journey and the corresponding water level support these observations: correlations were 0.86 on Route 1 and 0.66 on Route 2.

A more detailed assessment of how much of the variation in travel speed can be explained by different factors was done with a linear regression model. The results from the linear regression model (Table 4) show that, on average, $60 \%$ of the variation in travel speed can be explained by daily water level information and navigation direction (Model 1). The explanatory power of these two factors was highest along the Marañón River in 2013, where approximately $82 \%$ of the variation could be explained, and was lowest along the Amazon River during the same year (42\%). On average, $50-55 \%$ of the travel speed could be explained by knowing only the direction of navigation. Information on the daily water 
Table 3

Seasonal and directional differences along individual rivers in 2012 and 2013.

\begin{tabular}{|c|c|c|c|c|c|c|c|c|c|c|c|c|}
\hline \multirow[t]{3}{*}{ River } & \multirow[t]{3}{*}{ Seasons ${ }^{b}$} & \multicolumn{4}{|l|}{ Year 2012} & \multicolumn{4}{|l|}{ Year 2013} & & & \\
\hline & & \multicolumn{4}{|c|}{ Seasonal difference (\%) ${ }^{\mathrm{a}}$} & \multicolumn{4}{|c|}{ Seasonal difference (\%) ${ }^{\mathrm{a}}$} & \multicolumn{3}{|c|}{ Directional difference (\%) } \\
\hline & & Down- stream & $\mathrm{N}$ & Up- stream & $\mathrm{N}$ & Down- stream & $\mathrm{N}$ & Up- stream & $\mathrm{N}$ & Season & 2012 & 2013 \\
\hline \multirow[t]{3}{*}{ Amazon (anastomosing) } & HW vs. LW & 8.1 & 21 & 1.8 & 17 & 11.1 & 18 & 2.1 & 11 & HW & 34.0 & 18.6 \\
\hline & HW vs. I & 1.2 & 34 & 1.7 & 29 & 3.7 & 26 & 8.6 & 18 & I & 34.6 & 24.2 \\
\hline & I vs. LW & 6.8 & 31 & 0.1 & 30 & 7.1 & 28 & -5.9 & 19 & LW & 26.2 & 9.0 \\
\hline \multirow[t]{3}{*}{ Marañón (anastomosing) } & HW vs. LW & 1.8 & 7 & 1.3 & 19 & 16.3 & 14 & 11.3 & 15 & HW & 41.3 & 28.7 \\
\hline & HW vs. I & -6.4 & 11 & 0.9 & 33 & 6.6 & 18 & 16.2 & 23 & I & 52.4 & 40.4 \\
\hline & I vs. LW & 8.7 & 10 & 0.4 & 32 & 9.2 & 22 & -4.2 & 24 & LW & 40.6 & 23.1 \\
\hline \multirow[t]{3}{*}{ Ucayali (meandering) } & HW vs. LW & 27.5 & 19 & -10.2 & 6 & -10.0 & 6 & -11.9 & 9 & HW & 38.1 & 22.4 \\
\hline & HW vs. I & 8.9 & 29 & 9.5 & 17 & -4.8 & 10 & -6.8 & 11 & I & 38.9 & 19.7 \\
\hline & I vs. LW & 17.1 & 26 & -18.0 & 15 & -5.5 & 8 & -5.5 & 4 & LW & -2.7 & 19.7 \\
\hline \multirow[t]{4}{*}{ Huallaga (meandering) } & HW vs. LW & 18.0 & 9 & 14.3 & 11 & 10.2 & 12 & -2.4 & 15 & HW & 18.3 & 25.2 \\
\hline & HW vs. I & -0.3 & 15 & 4.2 & 19 & 4.1 & 14 & -3.1 & 19 & I & 23.7 & 16.5 \\
\hline & I vs. LW & 18.4 & 16 & 9.7 & 20 & 5.8 & 16 & 0.8 & 18 & LW & 14.6 & 10.9 \\
\hline & & & & & & & & & & Total: & 30.0 & 21.5 \\
\hline
\end{tabular}

c Seasons: High water (Mar/01-May/31); Low water (Aug/01-Oct/31); Intermediate (Jan/01-Feb/28 and Jun/01-Jul/31).

a Seasonal differences in travel speed are calculated with the formula: Season $1 /$ Season $2 * 100-100$.

b $\mathrm{HW}=$ High water; $\mathrm{I}=$ Intermediate; LW = Low water. level explains approximately $22-42 \%$ of the variation in downstream navigation ( $\max =74 \%$ ), and $5-10 \%$ of the variation in upstream navigation ( $\max =27 \%$ ). Thus, the combined use of navigation direction and water level statistics produces the best results when trying to predict the seasonal travel speed of vessels. See Supplement I for more details on other tested models.
4.4. Spatio-temporal examination of accessibility in Peruvian Amazonia

Fig. 3 illustrates the previous results in a geographical context and shows how far it is possible to travel within specific temporal constraints $(6 / 12 \mathrm{~h})$ along the navigation route from the selected
66

67

68
69

70

71

72

73

74

75

76

77

78

79

80

81

82

83

84

85

86

87

88

89

90

91

92

93

\section{ROUTE 1}
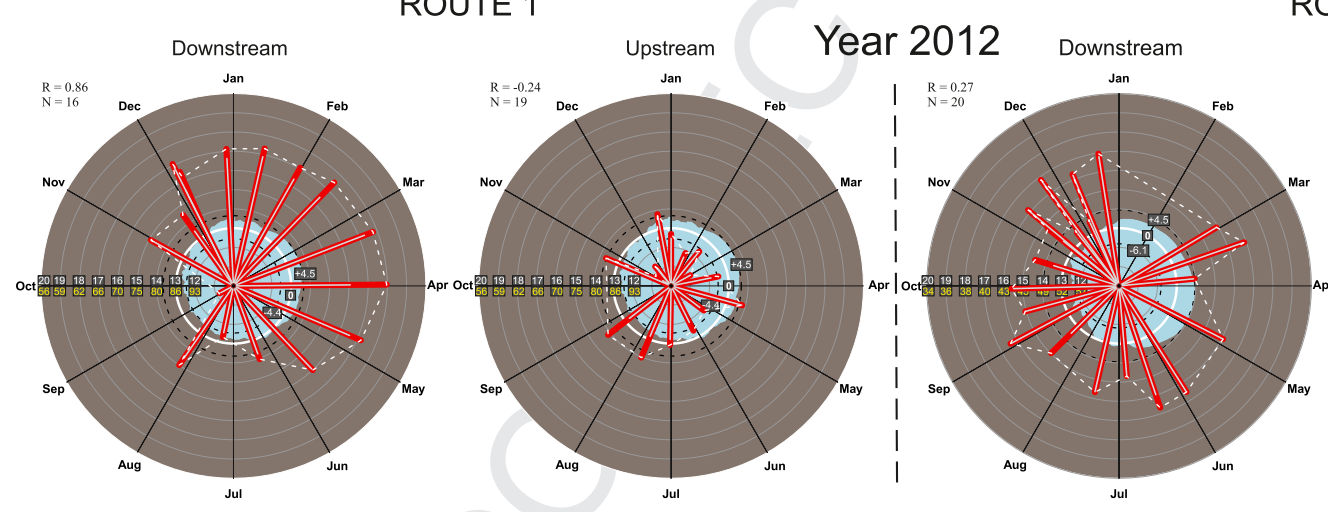

ROUTE 2
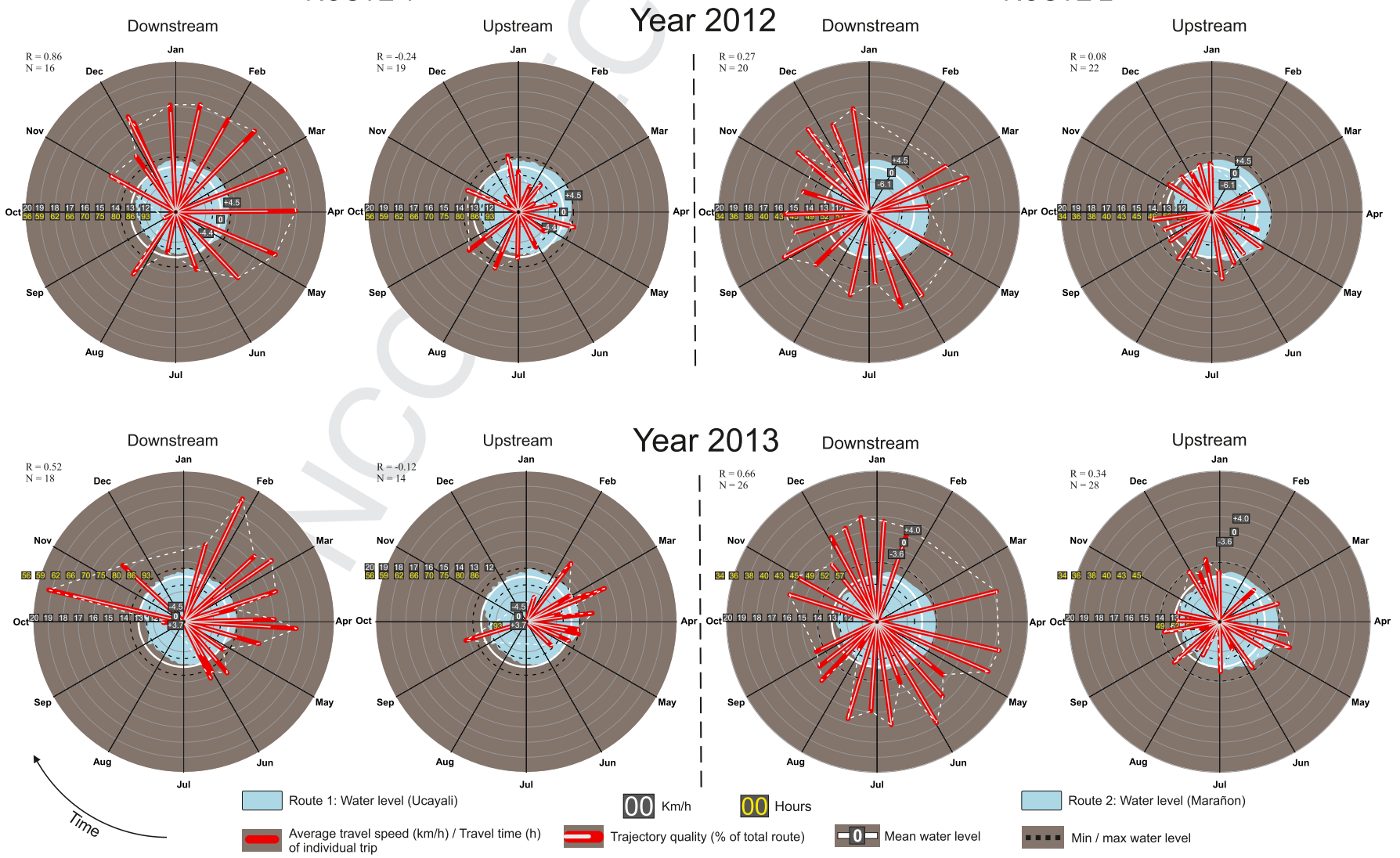

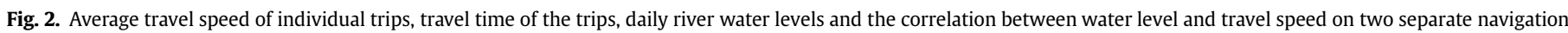
routes in 2012 and 2013. 
Table 4

Results from the linear regression model for individual rivers in 2012 and 2013 where travel speed is explained by daily water levels and navigation direction.

\begin{tabular}{|c|c|c|c|c|c|c|c|c|c|c|}
\hline \multirow{2}{*}{$\begin{array}{c}\text { Amazon } \\
\text { (anastomosing) }\end{array}$} & \multicolumn{2}{|c|}{ V1 } & \multicolumn{2}{|c|}{$\mathrm{V} 2$} & \multicolumn{2}{|c|}{ V3 } & \multicolumn{2}{|c|}{ V4 } & \multicolumn{2}{|c|}{$\begin{array}{l}\text { Weighted } \\
\text { Average }\end{array}$} \\
\hline & 2012 & 2013 & 2012 & 2013 & 2012 & 2013 & 2012 & 2013 & 2012 & 2013 \\
\hline $\mathrm{R}^{2}$ & $0.58^{* *}$ & $0.62^{*}$ & $0.41^{* * *}$ & $0.30^{* *}$ & 0.68 & - & $0.55^{* * *}$ & 0.96 & 0.51 & 0.42 \\
\hline Adjusted $\mathrm{R}^{2}$ & 0.52 & 0.53 & 0.37 & 0.26 & 0.35 & - & 0.51 & 0.92 & 0.45 & 0.37 \\
\hline $\mathrm{N}$ & 19 & 12 & 33 & 39 & 5 & 4 & 24 & 5 & 81 & 56 \\
\hline \multirow{2}{*}{$\begin{array}{c}\text { Ucayali } \\
\text { (meandering) }\end{array}$} & \multicolumn{2}{|c|}{ V1 } & \multicolumn{2}{|c|}{ V3 } & \multicolumn{2}{|c|}{ V5 } & & & \multicolumn{2}{|c|}{$\begin{array}{l}\text { Weighted } \\
\text { Average }\end{array}$} \\
\hline & 2012 & 2013 & 2012 & 2013 & 2012 & 2013 & & & 2012 & 2013 \\
\hline $\mathrm{R}^{2}$ & $0.47^{* * *}$ & $0.41^{\circ}$ & - & 0.50 & - & 0.57 & & & 0.47 & 0.48 \\
\hline Adjusted $\mathrm{R}^{2}$ & 0.43 & 0.33 & - & 0.00 & - & 0.48 & & & 0.43 & 0.25 \\
\hline $\mathrm{N}$ & 29 & 17 & - & 5 & 4 & 13 & & & 29 & 22 \\
\hline \multirow{2}{*}{$\begin{array}{c}\text { Marañón } \\
\text { (anastomosing) }\end{array}$} & \multicolumn{2}{|c|}{$\mathrm{V} 2$} & \multicolumn{2}{|c|}{ V3 } & \multicolumn{2}{|c|}{ V4 } & & & \multicolumn{2}{|c|}{$\begin{array}{l}\text { Weighted } \\
\text { Average }\end{array}$} \\
\hline & 2012 & 2013 & 2012 & 2013 & 2012 & 2013 & & & 2012 & 2013 \\
\hline $\mathrm{R}^{2}$ & $0.79^{* * *}$ & $0.81^{* * *}$ & 0.58 & - & $0.69^{* *}$ & 0.90 & & & 0.73 & 0.82 \\
\hline Adjusted $\mathrm{R}^{2}$ & 0.78 & 0.81 & 0.30 & - & 0.67 & 0.80 & & & 0.69 & 0.81 \\
\hline $\mathrm{N}$ & 36 & 50 & 6 & 3 & 37 & 5 & & & 79 & 50 \\
\hline \multirow{3}{*}{$\begin{array}{c}\text { Huallaga } \\
\text { (meandering) }\end{array}$} & \multicolumn{2}{|c|}{$\mathrm{V} 2$} & \multicolumn{2}{|c|}{ V3 } & & & & & \multicolumn{2}{|c|}{$\begin{array}{l}\text { Weighted } \\
\text { Average }\end{array}$} \\
\hline & 2012 & 2013 & 2012 & 2013 & & & $\begin{array}{l}\text { Wei } \\
\text { Ave }\end{array}$ & & 2012 & 2013 \\
\hline & $0.64^{* * *}$ & $0.63^{* * *}$ & 0.36 & - & & & 2012 & 2013 & 0.61 & 0.63 \\
\hline Adjusted $\mathrm{R}^{2}$ & 0.62 & 0.61 & -0.28 & - & & rivers $\mathbf{r}^{2}$ : & 0.60 & $\underline{0.60}$ & 0.51 & 0.61 \\
\hline $\mathrm{N}$ & 36 & 43 & 5 & 3 & & & & & 41 & 43 \\
\hline
\end{tabular}

Linear regression: $Y=\alpha+\beta 1+\beta 2+\square$, where:

$\mathrm{Y}=$ Average travel speed of vessel on an individual river stretch

V1 \& V5 navigate on the Amazon \& Ucayali

$\beta 1=$ Water level of the river on a navigation day, $\beta 2=$ Navigation direction

V2 navigate on the Amazon, Marañón \& Huallaga

$\square=$ Residual

V3 \& V4 navigate on the Amazon, Marañón,

Significance codes: $* * *=0, * *=0.001, *=0.01, \cdot=0.1$

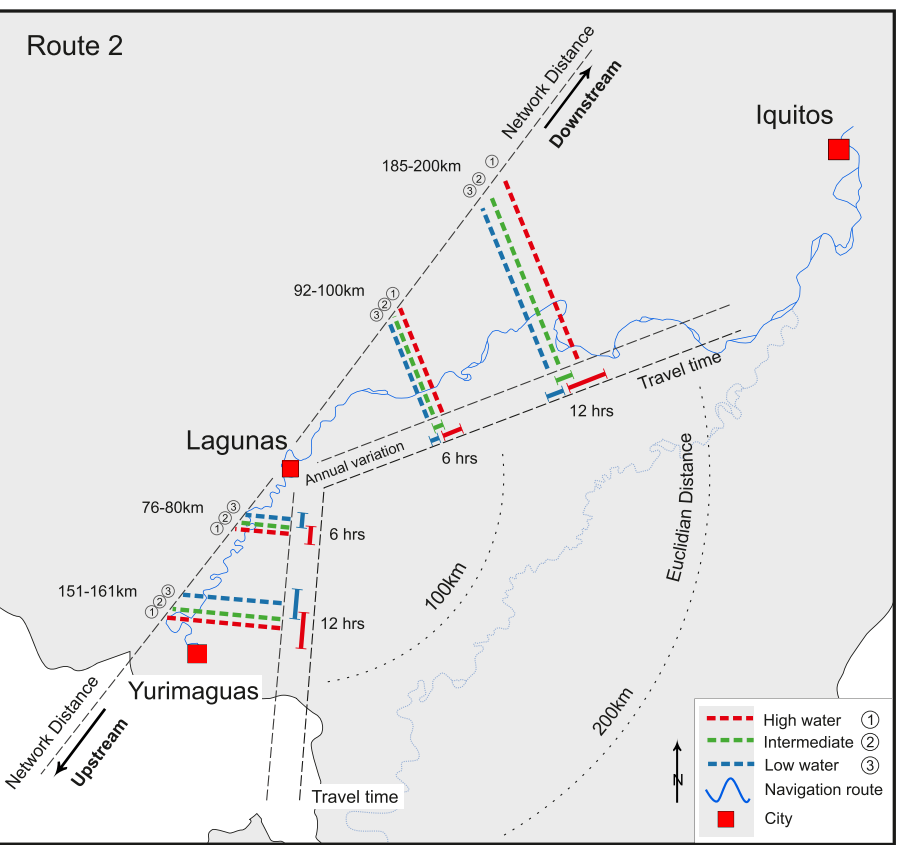

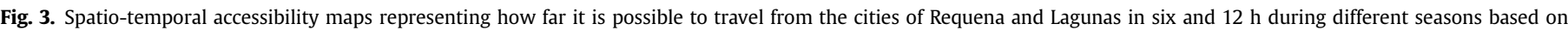
movement characteristics from AROS in 2012 and 2013. 
cities when travelling upstream or downstream (i.e., accessibility). Route 1 in Fig. 3 represents the accessibility from the city of Requena, which is located $244 \mathrm{~km}$ upstream from the city of Iquitos, and Route 2 shows the accessibility from the city of Lagunas, which is located $183 \mathrm{~km}$ downstream from Yurimaguas. The directional differences are clearly visible in the maps, as navigating downstream reaches $196 \mathrm{~km}$ at best on Route 1, while navigating upstream reaches only $169 \mathrm{~km}$ within $12 \mathrm{~h}$ (200 km vs. $161 \mathrm{~km}$ on Route 2). Results show that it is almost possible to reach Iquitos in $12 \mathrm{~h}$ from Requena (Route 1 ) during high water and the intermediate season, as the remaining distance was $48 \mathrm{~km}$ ( $3 \mathrm{~h}$ of travel), while during low water, the remaining distance and time are higher (90 km, 13 h of travel). When travelling upstream, the situation is reversed; travelling is fastest during low water and slowest during high water when the current of the river is strongest. On Route 2, however, it was fastest to navigate both upstream and downstream during high water and slowest during low water. The annual variation was generally highest during high water on both routes and lowest during low water (Route 1 ) or the intermediate season (Route 2).

\subsection{Interview results: perceived movement and navigation characteristics}

Interviews were used to understand the implications of navigation speeds on passengers travelling the routes. Eighty-one per cent of the respondents indicated the months from July to September as being the slowest navigation months on Route 1; however, on Route 2, the proportion was $79 \%$ (same months). On the contrary, the respondents thought that navigation was typically faster from October-April on both routes with a relatively even distribution of answers associated with each month ( $14 \%)$. Answers related to the directional differences in travel speeds indicate that, according to the respondents, downstream navigation is, on average, $15-23 \%$ (low water - high water) faster when compared to upstream navigation on Route 1 , and $30-42 \%$ faster on Route 2 . When asked about seasonal differences, approximately $65 \%$ thought that there were seasonal differences; they estimated that navigation was approximately 79\% (upstream) to $87 \%$ (downstream) faster during high water when compared to low water navigation (median $=50 \%$ faster for both directions). When asked about the accuracy of vessel departure times, the majority of respondents thought that the schedules were "Quite inaccurate" (55\% on Route $1,38 \%$ on Route 2 ). However, when asked about the importance of more accurately knowing the passing/departure schedules of the vessels, $92 \%$ and $76 \%$ of the respondents thought that it would be critically important on Route 1 and Route 2, respectively.

\subsection{Remarks on the validity of the results}

By looking at the temporal distribution of the tracked journeys in Fig. 2, it can be seen that the vessels have been moving regularly throughout 2012, i.e. having at least one travelled journey that was tracked per month/direction. In 2013, however, there are obvious gaps in the data, especially on Route 1 between June and September, which affects the representativeness of the results on Route 1 in 2013, and should be kept in mind when evaluating the results. The trajectory quality indicator (white line within red) (in the web version) shows that the values of individual journeys are fairly representative, since the percentage of tracked journeys (total route length) are clearly over $50 \%$, and, in most cases, the trackedjourney percentage is higher than $90 \%$, which indicates good representativeness.

\section{Discussion}

\subsection{Dynamic realities}

Our results confirm that accessibility in riverine environments is strongly affected by navigation direction (upstream vs. downstream navigation) and by seasonal variation in the water level of the rivers. The influence of these factors has been discussed before (Abad et al., 2013; Chibnik, 1994; Kvist et al., 2001); however, with the GPS-based mobility data, we were able to quantify and illustrate the rate of influence and explanatory power of seasonality and directionality on navigation and accessibility patterns.

Comparison of our result with information from existing literature, earlier measurements and local people (interviews) shows that our results are, broadly speaking, consistent with the previous findings, but we are able to quantify the temporal changes in more detail. Kvist et al. (2001) evaluated travel times from different Amazonian communities to Iquitos using the same navigation paths as in this study. Comparing these estimated travel times to our results shows that, on shorter distances (from Iquitos), the previous estimates correspond extremely well to the results of the current study. In some cases, however, there were differences that were probably caused by two factors: 1 ) our results excluded the stationary time that is spent on harbours and, therefore, underestimated the total travel time, and 2) the estimated travel times by Kvist et al. (2001) may have been overestimated because it is difficult to estimate travel times in a highly dynamic riverine environment due to high seasonal variation (as our results show) and even possible changes (such as cut-offs) in the navigation paths (Abizaid, 2005; Coomes et al., 2009). Comparing the current results to our earlier GPS-measurements (see Salonen et al., 2012) shows that the results are consistent with the earlier ones: travel time from, e.g. Requena to Iquitos, corresponds exactly to the two-year average time-distance ( $15 \mathrm{~h}$ ) during the same period (high water).

Local passengers are the most affected by the changing realities of transportation in the area. Comparing the GPS-based results to the information obtained from the local passengers - which essentially reveals people's perceptions of accessibility (see, e.g., Sanchez et al., 2000) - shows some interesting findings. Interviewees mostly agreed that there are seasonal and directional changes in travel times; however, when estimating the level of seasonal/directional variation in navigation, there were similarities, but also some essential differences, when compared to the GPSmeasured values. Respondents estimated that downstream navigation was approximately $28 \%$ faster compared to upstream navigation, which corresponds extremely well to the results of our GPSmeasurements (two-year average: $26 \%$ faster) - this is also an excellent example of how crowd wisdom can produce accurate estimates about a phenomenon (Christanakis \& Fowler, 2009; Galton, 1907; Pentland, 2014). In contrast, there were significant differences between passengers' estimations and the measured values when comparing the seasonal differences in navigation. Respondents estimated that travelling would take approximately $80 \%$ more time during the low water season compared to the high water season in both directions. However, the measured values indicate that seasonal differences are generally much lower (less than $30 \%$ ); moreover, when navigation direction changes (to upstream), it might even be faster to travel during the low water season when the current of the river is weak. Overall, it is possible to relate some findings to perceived accessibility from our study: estimating travel times is relatively easy with fairly recent memories producing quite accurate estimations (as in directional difference estimation), but is more difficult when using distant memories such as trying to estimate travel time of a trip that happened six months ago. 


\subsection{Applicability of the results in a wider context}

Our regression models support the idea that seasonal riverine transportation characteristics could be modelled by knowing the navigation direction and monthly average water levels of individual rivers. Thus, it could be possible to develop a universal model for estimating the navigation characteristics along different types of rivers while also taking into account seasonal variability. Creating such a universally applicable model would, of course, need more thorough research on different aspects affecting navigation (such as sinuosity and depth of rivers, estimated stationary times and design, size and equipment of the vessels, etc.), and also more detailed GPS-observations with higher sample rates than was available in our study case.

Our results - either treated as specific to the study area or extrapolated over larger areas - help us to better understand how riverine transportation functions along the dynamic river networks. The results could be useful for researchers as well as decision makers and planners responsible for the development of riverine transportation infrastructures. Quantification of average travel times, along with standard deviations, could, for instance, provide the foundation for a clearer transport schedule for the area (which was also desired by the local passengers), supporting the development of riverine transportation. Developing riverine transportation is a topical issue, given that the pressure in the next 30 years to build new roads is extremely high, and most are expected to be built in developing countries such as the ones covering Amazonia (Laurance et al., 2014). As opening new road connections is generally considered devastating in Amazonia, promoting the use of river transportation could be seen as a better option when compared to road building, since the former limits the human environmental impact by stopping only at specific places (Laurance, Goosem, \& Laurance, 2009). Improvements to river transportation offer possibly the least destructive alternative for enhancing the connectivity between South American areas: the waterways are naturally creating the transportation network through the densely forested areas. The development of such riverine transportation is also one of the key targets in (the much debated) IIRSA $^{2}$ that aims at improving the physical links and transportation infrastructure among the South American countries via highways, hydrovias (waterways) and energy projects (Killeen, 2007).

The results of this study could also provide more accurate data for modelling land use/land cover changes (such as deforestation, see Salonen et al., 2014) and socio-economic interactions, both of which are inherently strongly affected by the seasonality of the riverine transport environment (Perz et al., 2013; Soler, Escada, \& Verburg, 2009; Verburg, Overmars, \& Witte, 2004).

\section{Acknowledgements}

We thank Yully Rojas Reategui for assisting in field data collection in the Loreto and Ucayali regions. Fieldwork was supported financially by Nordenskiöld-samfundet. Additional funds for this research, including for the maintenance of AROS, were proQ6 vided by the Geography division at the University of Helsinki.

\section{Appendix A. Supplementary data}

Supplementary data related to this article can be found at http:// dx.doi.org/10.1016/j.apgeog.2015.07.003.

\footnotetext{
${ }^{2}$ Initiative for the Integration of the Regional Infrastructure of South America.
}

\section{References}

Abad, J., Vizcarra, J., Paredes, J., Montoro, H., Frias, C., \& Holguin, C. (2013). Morphodynamics of the upper Peruvian Amazonian rivers, implications into fluvial transportation. In Proceedings of the International conference IDS2013- Amazonia, 17-19 july 2013, iquitos, Peru.

Abizaid, C. (2005). Geographical field note. An anthropogenic meander cutoff along the Ucayali river, Peruvian Amazon. The Geographical Review, 95(1), 122-135.

Agarwal, S., Rahman, S., \& Errington, A. (2009). Measuring the determinants of relative economic performance of rural areas. Journal of Rural Studies, 25(3), 309-321.

Andrienko, N., Andrienko, G., Demsar, U., Dransch, D., Dykes, J., Fabrikant, S., et al. (2010). Space, time and visual analytics. International Journal of Geographical Information Science, 24(10), 1577-1600.

Andrienko, N., Andrienko, G., Pelekis, N., \& Spaccapietra, S. (2008). Basic concepts of movement data. In F. Giannotti, \& D. Pedreschi (Eds.), Mobility, data mining and privacy. geographic knowledge discovery. Verlag, Berlin: Springer.

Chibnik, M. (1994). Risky rivers: The economics and politics of floodplain farming in Amazonia. Tucson, Arizona: University of Arizona Press.

Christanakis, N., \& Fowler, J. (2009). Connected: The surprising power of our social networks and how they shape our lives (p. 353). New York, New York: Little Brown and Company.

Coomes, O. T., Abizaid, C., \& Lapointe, M. (2009). Human modification of a large meandering Amazonian River: genesis, ecological and economic consequences of the Masisea cutoff on the Central Ucayali, Peru. Ambio: A Journal of the Human Environment, 38(3), 130-134

Curtis, C., \& Scheurer, J. (2010). Planning for sustainable accessibility: developing tools to aid discussion and decision-making. Progress in Planning, 74, 53-106.

Demsar, U., \& Virrantaus, K. (2010). Space-time density of trajectories: exploring spatio-temporal patterns in movement data. International Journal of Geographical Information Science, 24(10), 1527-1542.

Dodge, S., Weibel, R., \& Lautenschütz, A. (2008). Towards a taxonomy of movement patterns. Information Visualization, 7, 240-252.

Downs, J., \& Horner, M. (2012). Probabilistic potential path trees for visualizing and analyzing vehicle tracking data. Journal of Transport Geography, 23, 72-80.

Farber, S., Morang, M., \& Widener, M. (2014). Temporal variability in transit-based accessibility to supermarkets. Applied Geography, 53, 149-159.

Galton, F. (1907). Vox populi. Nature, 75, 450-451.

Geurs, K., \& van Wee, B. (2004). Accessibility evaluation of land-use and transport strategies: review and research directions. Journal of Transport Geography, 12, 127-140.

Giannotti, F., \& Pedreschi, D. (2008). Mobility, data mining and privacy: a vision of convergence. In F. Giannotti, \& D. Pedreschi (Eds.), Mobility, data mining and privacy. Geographic knowledge discovery. Verlag, Berlin: Springer.

GOREL. (2006a). Mapa de la hidrografia principal y secundaria, departamento de Loreto. [Online] Available from http://www.regionloreto.gob.pe/OATSIG/5.pdf Accessed 22.03.12.

GOREL. (2006b). Mapa de infraestructura vial del departamento de Loreto. [Online] Available from http://www.regionloreto.gob.pe/OATSIG/8.pdf Accessed 22.03.12.

GOREL. (2006c). Mapa político del departamento de Loreto. [Online] Available from http://www.regionloreto.gob.pe/OATSIG/11.pdf Accessed 22.03.12.

Hansen, W. (1959). How accessibility shapes land use. Journal of American Institute of Planners, 25(1), 73-76.

INEI. (2012). Perú: Estimaciones y proyecciones de población total por sexo de las principales ciudades, 2000-2015. Instituto Nacional de Estadistica e Informatica. Boletín especial $\mathrm{N}^{\circ}$ 23. [Online] Available from http://proyectos.inei.gob.pe/ web/biblioineipub/bancopub/Est/Lib1020/index.html Accessed 10.12.14.

Ingram, D. (1971). The concept of accessibility: a search for an operational form. Regional Studies, 5, 101-107.

Järv, O., Ahas, R., \& Witlox, F. (2014). Understanding monthly variability in human activity spaces: a twelve-month study using mobile phone call detail records. Transportation Research Part C, 38, 122-135.

Kalliola, R., Salo, J., Puhakka, M., Rajasilta, M., Häme, T., Neller, R. J., et al. (1992). Upper Amazon channel migration - Implications for vegetation perturbance and succession using bitemporal landsat MSS images. Naturwissenschaften, 79(2), 75-79.

Karou, S., \& Hull, A. (2014). Accessibility modelling: predicting the impact of planned transport infrastructure on accessibility patterns in Edinburgh, UK. Journal of Transport Geography, 35, 1-11.

Killeen, T. (2007). A perfect storm in the Amazon wilderness: development and conservation in the context of the initiative for the integration of the regional infrastructure of South America (IIRSA). Advances in Applied Biodiversity Science, $7,102$.

Kirby, K., Laurance, W., Albernaz, A., Schroth, G., Fearnside, P., Bergen, S., et al. (2006). The future of deforestation in the brazilian Amazon. Futures, 38, 432-453.

Kvist, L. P., Gram, S., Cacares, C. A., \& Ore, B. I. (2001). Socio-economy of flood plain households in the Peruvian Amazon. Forest Ecology and Management, 150(1-2), 175-186.

Kvist, L., \& Nebel, G. (2001). A review of Peruvian flood plain forests: ecosystems, inhabitants and resource use. Forest Ecology and Management, 150, 3-26.

Kwan, M.-P. (2013). Beyond space (as we knew it): toward temporally integrated geographies of segregation, health, and accessibility. Annals of the Association of 
American Geographers, 10(5), 1078-1086.

Laurance, W., Albernaz, A., Schroth, G., Fearnside, P., Bergen, S., Venticinque, E., et al. (2002). Predictors of deforestation in the brazilian Amazon. Journal of Biogeography, 29, 737-748.

Laurance, W., Carolina Useche, D., et al. (2012). Averting biodiversity collapse in tropical forest protected areas. Nature, 489, 290-294.

Laurance, W., Clements, G., Sloan, S., O'Connell, C., Mueller, N., Goosem, M., et al. (2014). A global strategy for road building. Nature, 513, 229-232.

Laurance, W., Cochrane, M., Bergen, S., Fearnside, P., Delamônica, P., Barber, C., et al. (2001). The future of the brazilian Amazon. Science, 291, 438-439.

Laurance, W., Goosem, M., \& Laurance, S. (2009). Impacts of roads and linear clearings on tropical forests. Trends in Ecology and Evolution, 24(12), 659-669.

Makkonen, T., Salonen, M., \& Kajander, S. (2013). Island accessibility challenges: rural transport in the Finnish archipelago. European Journal of Transport and Infrastructure Research, 13(4), 274-290.

Marengo, J. (2005). Characteristics and spatio-temporal variability of the Amazon river basin water Budget. Climate Dynamics, 24, 11-22.

Ministerio de Transportes y Comunicaciones. (2010). Proyectos por departamentos. Informe -Departamento de Loreto. [Online] Available from http://www.mtc. gob.pe/portal/logypro/informes/Informes\%20abril2010/AM\%20Loreto\% 20v28Abril2010.pdf Accessed 10.12.14.

Olsson, J. (2009). Improved road accessibility and indirect development effects: evidence from rural Philippines. Journal of Transport Geography, 17(6), 476-483.

Pentland, A. (2014). Social physics: How good ideas spread - The lessons from a new science (p. 320). New York, New York: Penguin Press HC.

Perz, S., Qiu, Y., Xia, Y., Southworth, J., Sun, J., Marsik, M., et al. (2013). Transboundary infrastructure and land cover change: highway paving and community-level deforestation in a tri-national frontier in the Amazon. Land Use Policy, 34, 27-41.

Puhakka, M., Kalliola, R., Rajasilta, M., \& Salo, J. (1992). River types, site evolution and successional vegetation patterns in Peruvian Amazonia. Journal of Biogeography, 19(6), 651-665.

Reyes-García, V., Vadez, V., Aragón, J., Huanca, T., \& Jagger, P. (2010). The uneven reach of decentralization: a case study among indigenous peoples in the bolivian Amazon. International Political Science Review, 31(2), 229-243.

Rodriguez Achung, M. (1994). Crecimiento urbano de Iquitos: Condicionamientos estructurales en la decaca del '70 y sus perspectivas (p. 109). Iquitos: IIAP. Documento Técnico No 08.

Salo, J., Kalliola, R., Häkkinen, I., Mäkinen, Y., Niemelä, P., Puhakka, M., et al. (1986). River dynamics and the diversity of Amazon lowland forest. Nature, 322, 254-258.

Salonen, M., Maeda, E., \& Toivonen, T. (2014). Evaluating the impact of distance measures on deforestation simulations in the fluvial landscapes of Amazonia. AMBIO, 43(6), 779-790.

Salonen, M., Toivonen, T., Cohalan, J. M., \& Coomes, O. T. (2012). Critical distances: comparing measures of spatial accessibility in the riverine landscapes of peruvian Amazonia. Applied Geography, 32(2), 501-513.

Sanchez, J., Byfield, G., Brown, T. T., LaFavor, K., Murphy, D., \& Laud, P. (2000). Perceived accessibility versus actual physical accessibility of healthcare facilities. Rehabilitation Nursing, 25(1), 6-9.

SEHINAV. (2014). Servicio de hidrografia y navegación de la Amazonia. Marina de Guerra del Perú. [Online] Available from https://www.dhn.mil.pe/shna/index2. asp Accessed 10.12.14.

Shanley, P., Luz, L., \& Swingland, I. (2002). The faint promise of a distant market: a survey of Belém's trade in non-timber forest products. Biodiversity and Conservation, 11, 615-636.

Siedner, M. J., Lankowski, A., Tsai, A. C., Muzoora, C., Martin, J. N., Hunt, P. W., et al (2013). GPS measured distance to clinic, but not self-reported transportation factors, are associated with missed HIV clinic visits in rural Uganda. AIDS, 27(9), 1503-1508.

Sioli, H. (1984). The Amazon and its main affluents: hydrography morphology of the river courses and river types. In $\mathrm{H}$. Sioli (Ed.), The Amazon: Limnology and landscape ecology of a mighty tropical river and its basin (p. 763). Boston, Massachusetts: Junk Publishers.

Soler, L., Escada, M., \& Verburg, P. (2009). Quantifying deforestation and secondary forest determinants for different spatial extents in an Amazonian colonization frontier (Rondonia). Applied Geography, 29, 182-193.

SPOT. (2014). The SPOT personal tracker. Available from: http://www.findmespot.eu/ en/index.php?cid=101 Accessed 08.09.14.

Takasaki, Y., Barham, B., \& Coomes, O. T. (2001). Amazonian peasants, rain forest use, and income generation: the role of wealth and geographical factors. Society and Natural Resources, 14, 291-308.

Tenkanen, H., Salonen, M., Lattu, M., \& Toivonen, T. (2014). Geographic knowledge discovery from sparse GPS-data with $\mathrm{R}$ - Spatio-temporal examination of Amazonian river transports. In A. Jolma, P. Sarkola, \& L. Lehto (Eds.), Aalto university publication series, science + technology: 5. Proceedings of the 3rd open source geospatial research \& education symposium, OGRS 2014 (pp. 123-130).

Toivonen, T., Mäki, S., \& Kalliola, R. (2007). The riverscape of Western Amazonia - a quantitative approach to the fluvial biogeography of the region. Journal of Biogeography, 34(8), 1374-1387.

Vasconcellos, E. (1997). Rural transport and access to education in developing countries: policy issues. Journal of Transport Geography, 5(2), 127-136.

Verburg, P., Ellis, E., \& Letourneau, A. (2011). A global assessment of market accessibility and market influence for global environmental change studies. Environmental Research Letters, 6, 12.

Verburg, H., Overmars, K., \& Witte, N. (2004). Accessibility and land-use patterns at the forest fringe in the northeastern part of the Philippines. The Geographical Journal, 170(3), 238-255.

Willems, N., Van de Wetering, H., \& Wijk, J. (2009). Visualization of vessel movements. Computer Graphics Forum, 28(3), 959-966.

Zeng, N. (1999). Seasonal cycle and interannual variability in the Amazon hydrological cycle. Journal of Geophysical Research, 104, 9097-9106. 